J Aesth Chir 2008 - 1:6

DOI 10.1007/s12631-008-0006-7

(C) Springer Medizin Verlag 2008
H.G. Bull

St. Josefshospital Uerdingen, Krefeld

\title{
Journal für Ästhetische Chirurgie
}

\section{Ihre neue Fortbildungszeitschrift}

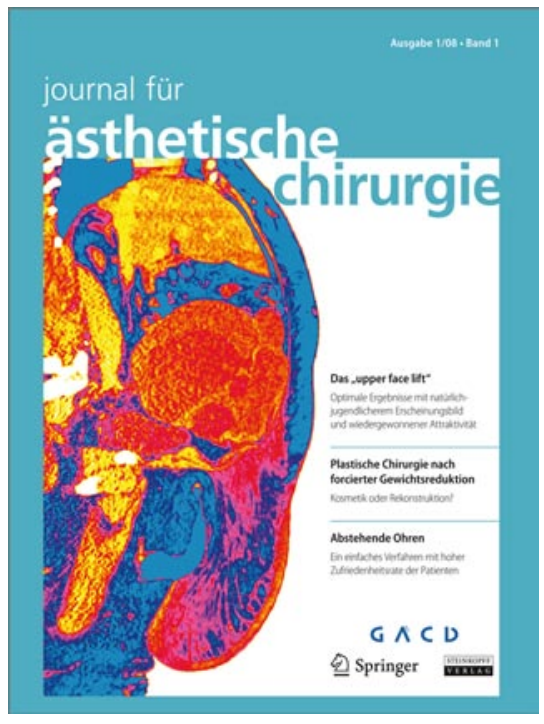

Sehr geehrte Frau Kollegin, sehr geehrter Herr Kollege,

mit der Ihnen vorliegenden ersten Ausgabe stellt sich das neue „Journal für Ästhetische Chirurgie“ im Springer Medizin Verlag als offizielles Organ der Gesellschaft für Ästhetische Chirurgie Deutschland e.V. vor. Mitglieder der Gesellschaft erhalten die Zeitschrift im Rahmen ihrer Mitgliedschaft.

Das Magazin, bisher einzigartig in Deutschland, ist nicht nur offizielles Organ der GÄCD sondern darüber hinaus auch wissenschaftliches Fachblatt, das alle in der Ästhetik tätigen Fachärzte ansprechen wird.

\section{(7) Das Journal für Ästhetische Chirurgie spricht alle in der Ästhetik tätigen Fachärzte an}

Das „Journal für Ästhetische Chirurgie“ wird 4-mal im Jahr erscheinen, d. h. im Januar, April, Juli und Oktober, und durch wissenschaftliche Originalarbeiten die ästhetische Chirurgie und Medizin in Deutschland bereichern und vertiefen.

Hiermit soll ein deutliches Zeichen der Gesellschaft gesetzt werden, in einem Jahrhundert, in dem die ästhetische Chirurgie einen immer größer werdenden Stellenwert besitzt. Deshalb müssen wir uns besonders der ärztlichen und ethischen Verantwortung in diesem außerordentlich sensiblen aber zugleich faszinierenden Teilgebiet der Gesamtmedizin bewusst sein. Um dieser Verantwor- tung gerecht zu werden, soll die interdisziplinäre Diskussion gefördert und ausgebaut werden.

Da die Geschichte der ästhetischen und plastischen Chirurgie in Deutschland eine Geschichte der regionalen und organbezogenen plastischen Chirurgie ist, ist die Gesellschaft für Ästhetische Chirurgie Deutschland e.V. als interdisziplinäre Gesellschaft besonders aufgerufen diese Tradition zu pflegen und zu erweitern. Dies wird uns mit Hilfe des neuen Journals sicherlich gelingen.

Ich wünsche dem Journal eine gute Entwicklung zum Wohl der gesamten ästhetischen Chirurgie und der Gesellschaft und Ihnen beim Lesen dieser ersten Ausgabe eine anregende Lektüre.

Alle Mitglieder der Gesellschaft und Leser sind zu Anregungen und zur Mitarbeit bei der inhaltlichen Gestaltung unseres Journals herzlich aufgerufen.

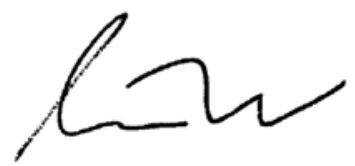

Prof. Dr. Dr. med. H.G. Bull Präsident der GÄCD

\section{Korrespondenzadresse}

Prof. Dr. Dr. H.G. Bull

St. Josefshospital Uerdingen Kurfürstenstr. 69, 47829 Krefeld bull.mkg@stjosef.de 